\title{
Development of sol-gel formulations for slow release of pheromones
}

\author{
Anat Zada $\cdot$ Lily Falach $\cdot$ John A. Byers
}

Received: 17 November 2008/ Accepted: 20 January 2009/Published online: 12 February 2009

(c) Birkhäuser Verlag, Basel/Switzerland 2009

\begin{abstract}
A new type of dispenser for slow-release of sex pheromones and other semiochemicals was developed based on sol-gel polymers that can be useful for monitoring, mass trapping, and mating disruption in integrated pest management (IPM). Sol-gel matrices exhibit glass characteristics and allow control of the degree of crosslinking during the polymerization process in order to provide an optimal release rate for a particular pheromone. The advantages of sol-gel (silica) matrixes include keeping the added molecules chemically stable and enabling the sol-gel material to be applied in any desired thickness and pheromone quantity, and thereby readily modify release rates. In addition, sol-gels are primarily silica and water that are common in the environment and therefore safe for field dispensing. We developed a method for the entrapment of pheromones in sol-gel matrices that allowed release at an almost constant rate over many days in the field. For example, $2.5 \mathrm{mg}(E)$-5-decenyl acetate pheromone of peach twig borer, Anarsia lineatella, entrapped in various sol-gel formulations released $14-45 \mu \mathrm{g} /$ day for up to 28 days. The codling moth (Cydia pomonella) pheromone in sol-gels was used in field tests to capture more codling moth males than unbaited control traps. We describe how the method may be modified to entrap other types of pheromones by making sol-gels with different pore sizes.
\end{abstract}

\footnotetext{
A. Zada $(\bowtie) \cdot$ L. Falach

Department of Entomology-Chemistry, Institute of Plant Protection, Agricultural Research Organization, POB 6, Bet Dagan 50250, Israel

e-mail: anatzada@volcani.agri.gov.il

J. A. Byers

US Arid-Land Agricultural Research Center, USDA-ARS, 21881 North Cardon Lane, Maricopa, AZ 85238, USA
}

Keywords Sol-gel · Dispenser - Pheromone · Semiochemicals $\cdot$ Lure $\cdot$ Release rates $\cdot$ Anarsia lineatella $\cdot$ Cydia pomonella

\section{Introduction}

In agriculture and forestry, monitoring of pest insect populations uses baits containing microgram to milligram quantities of pheromones (Knutson et al. 1988; McLaughlin and Heath 1989; Bartelt et al. 1994), while control of pest populations by mating disruption or mass trapping uses formulations deployed at higher densities and total amounts (Stelinski et al. 2005, 2007a, b; El-Sayed et al. 2006; Miller et al. 2006a, b; Byers 2007). The development of an insect pest management system employing mating disruption or mass trapping with pheromones, as well as pest monitoring, requires devices or dispensers that release compounds over long periods (Bierl-Leonhardt 1982). Most pheromone components vaporize quickly if not formulated in an appropriate controlled-release dispenser. Ideally, the release rate of the pheromone should be relatively constant and remain effective during the whole flight period of the pest. Often the sensitivity of various pheromone components to UV and oxidation are poorly known and little attempt is made to protect the components in the field (Ideses and Shani 1988). Thus, it is desirable that a dispenser-formulation protect pheromone from oxidation and degradation by UV light. This can be achieved by entrapment of the active ingredient in a protective matrix and by the addition of antioxidants and UV inhibitors (Knutson et al. 1988; Ideses and Shani 1988; Millar 1995; Cork et al. 2008).

The matrix that holds and releases the pheromones plays a significant role in the success of the monitoring or 
mating-disruption systems (Wilkins et al. 1984; Zdarek et al. 1988; Chamberlain et al. 2000). There are several successful commercial formulations made of polyethylene tubes, cotton rolls, ropes, or bags baited with pheromones (Brown et al. 1992; Suckling 2000; Johansson et al. 2001). However, problems may arise when the matrix does not preserve the pheromone and allows either too high a release that exhausts the dispenser too soon, or too low a release that is less than optimal primarily depending on the volatility of the components. Wax dollops and similar materials are increasingly being used to dispense pheromone from many sources in mating disruption (Atterholt et al. 1998; Stelinski et al. 2005, 2007a; deLame et al. 2007). These systems allow various quantities to be dispensed at various densities in the field in order to optimize coverage, perhaps aided by EAR (effective attraction radius) and mass trapping/mating disruption models (Byers 2007, 2008; El-Sayed et al. 2006). However, wax dollops and in fact most materials (e.g., rubber septa) release volatiles as a declining exponential function (Flint et al. 1978; Bierl-Leonhardt 1982; Vrkoč et al. 1988; Byers 1988; McDonough 1991; Knight 1995; Zada et al. 2002; Stelinski et al. 2005). This means that the release rate is high immediately after adding the volatiles to the substrate, and then the rate diminishes gradually. This type of release curve would imply the wasting of pheromone initially, then reaching an optimal rate, and later as time progressed diminishing amounts would mean increasingly limited efficacy.

When the pheromone is unstable, usually in the case of aldehydes and polyene compounds, the bait loses its effectiveness rapidly in a matter of a few days. For example, the main pheromone component of the spiny bollworm Earias insulana (Boisduval), a severe cotton pest, is $(10 E, 12 E)$-hexadecadienal (Dunkelblum et al. 1984) and that of the carob moth Ectomyelois ceratoniae Zeller, a serious pest of dates, citrus and other crops, is (9Z,11E,13)-tetradecatrienal (Todd et al. 1992). Neither of these compounds can be stabilized in standard lures, and they lose their attractiveness within a short period in the field.

Sol-gels are inorganic polymers of metal alkoxides (usually silicates) that exhibit glass properties and are chemically inert (Kandimalla et al. 2006; Zayat et al. 2007). A three-dimensional gel network is produced by the condensation of partially hydrolyzed components, and its porous microstructure is determined by the rate of particle growth and the extent of cross-linking. More specifically, sol-gel formation is controlled by the relative rates of hydrolysis and condensation (Fig. 1). Most molecules can be entrapped in a sol-gel matrix, and they usually retain their characteristic physical and chemical properties (Avnir 1995). Large-molecular-weight bioorganic molecules such as enzymes, whole cells, antibodies and proteins have been entrapped successfully (Kroschwitz and Howe-Grant 1998). Silica aerogels are unique porous materials that often consist of less than $10 \%$ silicon dioxide and more than $90 \%$ air. Because of the high porosity of sol-gels and the ability to vary their density in a controlled manner, they are potential candidates for use as a new type of pheromone-release device. Sol-gels are also environmentally friendly materials because their main decomposition products are non-toxic.

Our first objective was to investigate the properties and preparation methods of various sol-gel formulations as potential slow-release devices of moth pheromones that have different functional groups (alcohol, acetate, and aldehyde) and chain lengths. Secondly, we wanted to measure the release rate of a moth sex pheromone (peach twig borer, Anarsia lineatella Zeller) from various sol-gel preparations in the field to determine which formulations provided a constant release. Finally, we wanted to indicate the potential of further development of sol-gels in applied control programs by showing that several possible formulations can attract codling moths, Cydia pomonella (L.), in the field.

\section{Materials and methods}

\section{Chemicals}

All fine chemicals were purchased from Aldrich (St. Louis, MO, USA) unless stated otherwise, and were used without further purification. Solvents were purchased from BioLab (Jerusalem, Israel), $\mathrm{HCl}$ and $\mathrm{NH}_{4} \mathrm{OH}$ from Merck
Fig. 1 General synthesis of sol-gels. ( $\mathrm{R}=$ alkyl nonhydrolyzable group, $n>m$ )

$$
\begin{aligned}
& \mathrm{Si}\left(\mathrm{OCH}_{3}\right)_{4} \stackrel{\mathrm{H}_{2} \mathrm{O}^{+} \mathrm{H}^{+} \mathrm{OH}^{-}}{\longrightarrow} \mathrm{Si}\left(\mathrm{OCH}_{3}\right)_{3} \mathrm{OH}+\mathrm{CH}_{3} \mathrm{OH} \\
& \mathrm{Si}\left(\mathrm{OCH}_{3}\right)_{3} \mathrm{OH}+\mathrm{Si}\left(\mathrm{OCH}_{3}\right)_{3} \mathrm{OH} \longrightarrow\left(\mathrm{OCH}_{3}\right)_{3} \mathrm{Si}-\mathrm{O}-\mathrm{Si}(\mathrm{OCH} 3)_{3} \rightarrow \rightarrow-\left(\mathrm{SiO}_{2}\right) \mathrm{n}-
\end{aligned}
$$

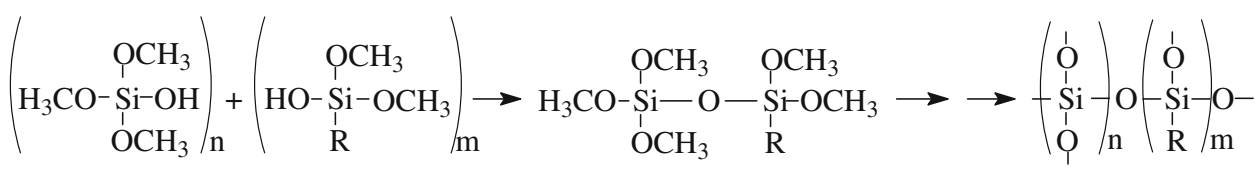


(Darmstadt, Germany) and moth pheromones from Bedoukian (Danbury, CT, USA). Sol-gel silicates were used as follows: TMOS (tetramethoxy orthosilicate), MTMOS (methyltrimethoxy orthosilicate), ETMOS (ethyltrimethoxy orthosilicate), PTMOS (propyltrimethoxy orthosilicate), and OTMOS (octyltrimethoxy orthosilicate).

Effect of water/TMOS ratios, $\mathrm{pH}$, solvents, and surfactants on sol-gel preparation

One $\mathrm{ml}(\times 1)$ of TMOS was mixed with various ratios of $0.48(\times 4), 0.73(\times 6), 0.97(\times 8)$, or $1.25(\times 10) \mathrm{ml}$ of $0.001 \mathrm{M}$ $\mathrm{HCl}$ by vigorously stirring in a test tube with a vortex machine to obtain a homogeneous sol (solution prior to gelling). The alcohol was removed by gentle warming $\left(40^{\circ} \mathrm{C}\right)$ in a rotavaporator as described by Ferrer et al. (2002). The tube was weighed periodically until all of the methanol had evaporated, $100 \mu \mathrm{l}$ of $2 \%$ Tween 20 in methanol was added, the solution was stirred, and $0.2 \mathrm{ml}$ of $0.049 \mathrm{M}$ $\mathrm{NH}_{4} \mathrm{OH}$ added to complete the gelling process. A gel was formed after a few seconds. The tube was kept at room temperature for five days and then stored in a refrigerator.

The effect of $\mathrm{pH}$ was tested with a mixture of $1 \mathrm{ml}$ of TMOS and $1 \mathrm{ml}$ of $0.001 \mathrm{M} \mathrm{HCl}$ stirred vigorously in a test tube by means of a vortex machine to obtain a homogeneous sol. After the methanol had evaporated as described above, $100 \mu \mathrm{l}$ of $2 \%$ Tween 20 in methanol was added, the solution stirred, and $0.025,0.05,0.1$ or $0.2 \mathrm{ml}$ of $0.049 \mathrm{M} \mathrm{NH}_{4} \mathrm{OH}$ was added to complete the gelling.

The effect of solvent was explored with a mixture of $1 \mathrm{ml}$ of TMOS and $1 \mathrm{ml}$ of $0.001 \mathrm{M} \mathrm{HCl}$ stirred vigorously in a test tube by means of a vortex machine to obtain a homogeneous sol. After the methanol had evaporated as described above, $100 \mu \mathrm{l}$ of $2 \%$ Tween 20 in methanol or THF (tetrahydrofurane) or acetone was added, the solution stirred, and $0.2 \mathrm{ml}$ of $0.049 \mathrm{M} \mathrm{NH}_{4} \mathrm{OH}$ added to complete the gelling. After five days at room temperature all the gels had solidified.

Using the same procedure as described above, we tested the addition of the following surfactants (dissolved in methanol): (1) a cationic surfactant, hexadecyl pyridinium chloride hydrate; (2) an anionic surfactant, sodium laurylsulfate; (3) two non-ionic surfactants, Tween 20 and PEG600; and (4) dioctylphthalate, as a polymeric softening agent.

Preparation of copolymers of TMOS and MTMOS containing pheromones with various functional groups and chain lengths

A mixture of $0.95 \mathrm{ml}$ of TMOS, $0.1 \mathrm{ml}$ of MTMOS and $1 \mathrm{ml}$ of $0.001 \mathrm{M} \mathrm{HCl}$ was vigorously stirred in a test tube by means of a vortex machine to obtain a homogeneous sol. The alcohol was removed as described above. After the methanol had evaporated, $100 \mu \mathrm{l}$ of $2 \%$ Tween 20 in methanol and $1 \mathrm{mg}$ of each pheromone dissolved in $100 \mu \mathrm{l}$ of methanol were added. The solutions were stirred quickly and $0.2 \mathrm{ml}$ of $0.049 \mathrm{M} \mathrm{NH} \mathrm{NH}_{4} \mathrm{OH}$ added to complete the gelling. The following pheromones were entrapped: (1) (Z)-11-hexadecenal (cotton bollworm, Helicoverpa armigera); (2) $(7 Z, 11 E)$-hexadecadienyl acetate $+(7 Z, 11 Z)$ hexadecadienyl acetate 1:1 [pink bollworm, Pectinophora gossypiella (Saunders)]; (3) (Z)-7-dodecenyl acetate (a common component of moth pheromones); and (4) (8E,10E)-dodecadienol (codling moth, Cydia pomonella). After five days at room temperature all gels had solidified although they were slightly turbid.

Effect of increasing ratio of TMOS to MTMOS, ETMOS, PTMOS, or OTMOS

TMOS was mixed with each of either MTMOS, ETMOS, PTMOS, or OTMOS in ratios of 400, 200, 100, 50, 40, 30, 20,10 or $5 \%$ in a test tube to obtain $1-\mathrm{ml}$ volumes of the mixtures. One milliliter of $0.001 \mathrm{M} \mathrm{HCl}$ was added to each mixture which was vigorously stirred with a vortex machine to obtain a homogeneous sol. After the methanol was removed, $1 \mathrm{mg}$ of (Z)-7-dodecenyl acetate, or $(9 Z, 11 E)$-tetradecadienyl acetate (pheromone component of Egyptian cotton leafworm, Spodoptera littoralis), and $1 \mathrm{mg}$ of PEG600, both dissolved in $100 \mu \mathrm{l}$ of methanol, were added and mixed, and $0.2 \mathrm{ml}$ of $0.049 \mathrm{M} \mathrm{NH}_{4} \mathrm{OH}$ added to complete the gelling.

Release rates of peach twig borer pheromone from sol-gels in the field

Sol-gels of TMOS and 10, 20 or 30\% MTMOS, ETMOS and PTMOS containing peach twig borer pheromone were prepared with TMOS and appropriate amounts (10, 20 or $30 \%$ ) of either MTMOS, ETMOS, or PTMOS, and $1 \mathrm{ml}$ of $0.001 \mathrm{M} \mathrm{HCl}$. Each mixture was stirred as described above. Then $100 \mu \mathrm{l}$ of $10 \%$ Tween 20 in methanol and peach twig borer pheromone [2.5 mg of $(E)$-5-decenyl acetate] dissolved in $100 \mu \mathrm{l}$ of methanol were added. The solution was stirred quickly and $0.2 \mathrm{ml}$ of $0.049 \mathrm{M} \mathrm{NH}_{4} \mathrm{OH}$ added to complete the gelling. After five days the gels were rolled in an aluminum foil and kept at $4{ }^{\circ} \mathrm{C}$ pending use.

Sol-gels glass wrapped in perforated cotton cloths (to avoid scattering of glass particles during degradation) were hung under a tree in Bet Dagan, Israel (July 29 to August 26, 2004). From three to five samples were taken for analysis after $0,3,7,14,21$ and 28 days. The samples were dissolved in $2 \mathrm{ml}$ of methanol and shaken for $2 \mathrm{~h}$ in an ultrasonic bath (Model 3510; Branson, Danbury, CT, USA) cooled with ice. Aliquots of $50 \mu \mathrm{l}$ were transferred into a mixture of $0.5 \mathrm{ml}$ 
$n$-hexane and $0.5 \mathrm{ml} \mathrm{H}_{2} \mathrm{O}$, plus $50 \mu \mathrm{g}$ of (Z)-7-dodecenyl acetate dissolved in $50 \mu \mathrm{l} n$-hexane as an internal standard. After the mixture had been shaken, the organic phase was separated and dried with $\mathrm{MgSO}_{4}$ pending GC analysis. Onemicroliter samples were injected and analyzed by GC (Model 6890; Hewlett-Packard, Wilmington, DE, USA), equipped with an Agilent HP5 column $(30 \mathrm{~m} \times 0.25 \mathrm{~mm}$ ID, $0.25 \mu \mathrm{m}$ coating). The column was kept at $60^{\circ} \mathrm{C}$ for $2 \mathrm{~min}$ and then programmed to $180^{\circ} \mathrm{C}(4 \mathrm{~min})$ at a rate of $20^{\circ} \mathrm{C} / \mathrm{min}$. The quantity of pheromone was calculated in accordance with the ratio between the detector responses to the pheromone and internal standard. Linear regression (Sokal and Rohlf 1995) was performed on the amounts left from day 3 (after apparent equilibrium) to day 21 (before pheromone release apparently ceased).

Testing sol-gels of TMOS and PTMOS with codling moth pheromone in the field

A mixture of TMOS and the appropriate amount $(2,5,10$ or $30 \%$ ) of PTMOS and $1 \mathrm{ml}$ of $0.001 \mathrm{M} \mathrm{HCl}$ was vigorously stirred in a test tube by means of a vortex machine to obtain a homogeneous sol. After the methanol had evaporated, $100 \mu \mathrm{l}$ of $10 \%$ Tween 20 in methanol and $0.5,1.0,2.0$, or $10.0 \mathrm{mg}$ of codling moth pheromone $(8 E, 10 E)$-dodecadienol dissolved in methanol were added. The solution was stirred quickly and $0.2 \mathrm{ml}$ of $0.049 \mathrm{M} \mathrm{NH}_{4} \mathrm{OH}$ added to complete the gelling. After five days the gels were rolled in an aluminum foil and kept at $4{ }^{\circ} \mathrm{C}$ pending use.

Codling moth (Cydia pomenella) is a pest of apples, pears and walnuts (Stelinski et al. 2007b and references therein), hence the field tests were conducted in a walnut orchard in Kibbutz Tzuba. Various sol-gels wrapped in perforated cotton cloths (to avoid scattering of glass particles during degradation under field conditions) were hung in funnel traps (IPS) compared to an empty trap. DDVP (dichlorvos insecticide) dispensers were put in all traps to kill any trapped males. Five replicates of traps with each treatment were exposed in a codling moth-infested walnut orchard in Kibbutz Tzuba, near Jerusalem. The traps were hung randomly in separate rows of trees, with one trap of each treatment in each row. Treatments were compared to unbaited control traps by $\mathrm{t}$-tests after square-root (value +0.5 ) transformation (Sokal and Rohlf 1995).

\section{Results}

Effect of water/TMOS ratios, $\mathrm{pH}$, solvents, and surfactants on sol-gel preparation

In developing a new method for the preparation of sol-gels containing pheromones we found that the best water/TMOS ratio for the gels was $8: 1$, since gels prepared with other ratios developed cracks after a few days at room temperature. The $\mathrm{pH}$ also is an important factor in successful preparation of sol-gels because $\mathrm{pH}$ influences the rates of both hydrolysis of the TMOS and condensation of the hydrolyzed monomers. Except for MTMOS, none of the alkyl trimethoxyorthosilicates hydrolyzed rapidly at $\mathrm{pH} 7$, thus hydrolysis of TMOS was accelerated in a slightly acidic medium. After addition of the pheromone, a base should be added to promote rapid condensation. Addition of an excess of an ammonium base, such as 10 times the molar amount of acid, prevented the formation of cracks. The solvent in which the pheromone and the surfactant were dissolved was also important. THF and acetone have a lower surface tension than water and methanol, therefore using THF/acetone reduces the capillary pressure that could cause the collapse of the porous structure. However, since we did not observe any differences between THF, methanol and acetone, we chose methanol as the preferred solvent.

A surfactant was an important additive in the sol-gel preparation, mainly to prevent cracking. Usually the gel was dried in glass tubes, and the surfactant can reduce the mutual affinity between the gel and glass; the surfactant can also increase the affinity between the gel and pheromone. Gels were obtained without cracks only when non-ionic surfactants were used. However, when (Z)-7-dodecenyl acetate was added, we noticed that PEG600 gave transparent gels whereas Tween 20 did not. Since transparency indicates homogeneity, PEG600 was selected as the surfactant.

\section{Preparation of copolymers of TMOS and MTMOS} containing pheromones with various functional groups and chain lengths

Four pheromones with various functional groups and chain lengths common in many moth pheromones (Byers 2006; El-Sayed 2008) were entrapped in gels of TMOS and 5\% MTMOS: 1. (Z)-11-hexadecenal (cotton bollworm); 2. $(7 Z, 11 E)$ - haxadecadienyl acetate $+(7 Z, 11 Z)$-hexadecadienyl acetate in a 1:1 mixture (pink bollworm); 3. (Z)-7dodecenyl acetate (a common moth pheromone component); and 4. (8E,10E)-dodecadienol (codling moth). After 5 days at room temperature, all the gels had solidified, although they remained slightly turbid and their structures (rods of approximately 2-cm length and $8-\mathrm{mm}$ diameter) were preserved even after 3 months under these conditions.

\section{Effect of increasing ratio of TMOS to MTMOS, ETMOS, PTMOS, or OTMOS}

The effect of increasing the proportion of alkyl trimethoxy orthosilicate in the sol-gels was studied by using TMOS in proportions of $400,200,100,50,40,20,10$, or $5 \%$ with 
either MTMOS, ETMOS, PTMOS, or OTMOS, together with $1 \mathrm{mg}$ of (Z)-7-dodecenyl acetate (Figs. 2 and 3). The results indicate that generally the gel became more transparent as the relative amount of TMOS was increased. However, with OTMOS, the polymerization proceeded very slowly and produced white and very brittle solids, indicating that OTMOS was not suitable for preparation of sol-gels by this method. The longer alkyl group in these comonomers results in brittle solid gels at lower concentrations of the comonomer (Figs. 2 and 3). The concentration of the PTMOS comonomer affected the transparency of the gels doped with the pheromone (9Z,11E)-tetradecadienyl acetate (Egyptian cotton leafworm): the gels became more transparent at higher concentrations of PTMOS (Fig. 4).

Release rates of peach twig borer pheromone from sol-gels in the field

Generally, under outdoor conditions the various sol-gel formulations containing peach twig borer component $E-5$ -

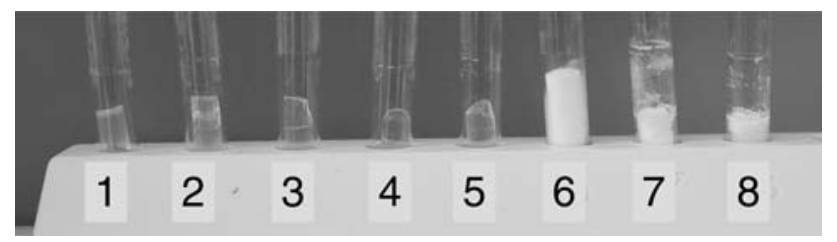

Fig. 2 Copolymers of TMOS and ETMOS. Sol-gels marked 1-8 contain 5, 10, 20, 40, 50, 100, 200 and 400\%, respectively, of ETMOS, and the pheromone (Z)-7-dodecenyl acetate

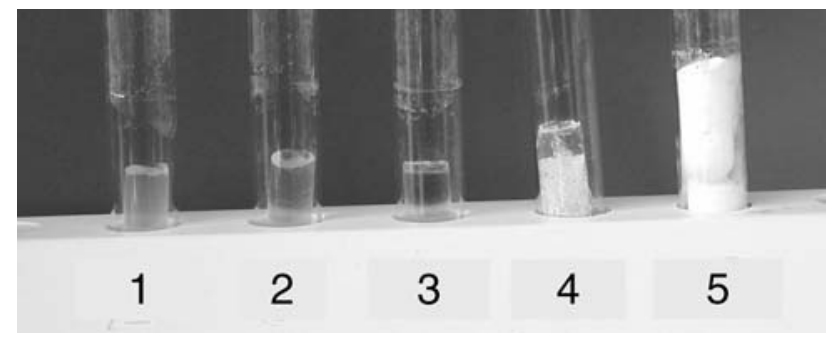

Fig. 3 Copolymers of TMOS and PTMOS. Sol-gels marked 1-5 contain 5, 10, 20, 40 and 50\%, respectively, of PTMOS, and pheromone (Z)-7-dodecenyl acetate

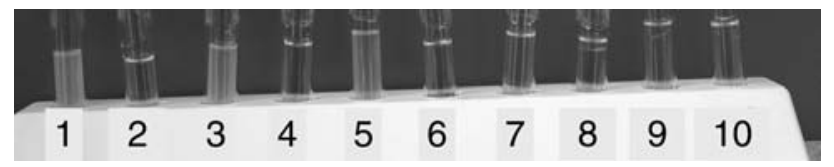

Fig. 4 Copolymers of TMOS and PTMOS. Sol-gels marked 1, 3, 5, 7 and 9 contain 5,10,20,30 and 40\%, respectively, of PTMOS, and pheromone $(9 Z, 11 E)$-tetradecadienyl acetate. Sol-gels marked 2, 4, 6, 8 and 10, respectively, contain the same percentages of the alkyl trimethoxysilane (PTMOS) comonomer but no pheromone decenyl acetate lasted at most 28 days (Figs. 5, 6, 7). The release rates became rather constant after a short period (before day 3 ) apparently when reaching an equilibrium in release rate (Figs. 5, 6, 7). Sometime after day 21, most sol-gels stopped releasing pheromone because the amounts left on day 28 did not decline appreciably (Figs. 5, 6, 7). Thus, data from day 3-21 were used in the linear regressions (dashed lines) to report release rates (slope $=$ amount released per day) that were relatively constant as indicated by higher $R^{2}$ (Figs. 5, 6, 7). However, there were no significant differences in the pheromone release rates from the various matrices, nor any significant differences due to comonomer/TMOS proportions, probably because of variations in the pore size of each of the matrices, a factor that also affected the reproducibility of the results ( $R^{2}$ values).

Testing sol-gels of TMOS and PTMOS with codling moth pheromone in the field

Field tests were conducted with the codling moth pheromone using TMOS/PTMOS gels because this matrix

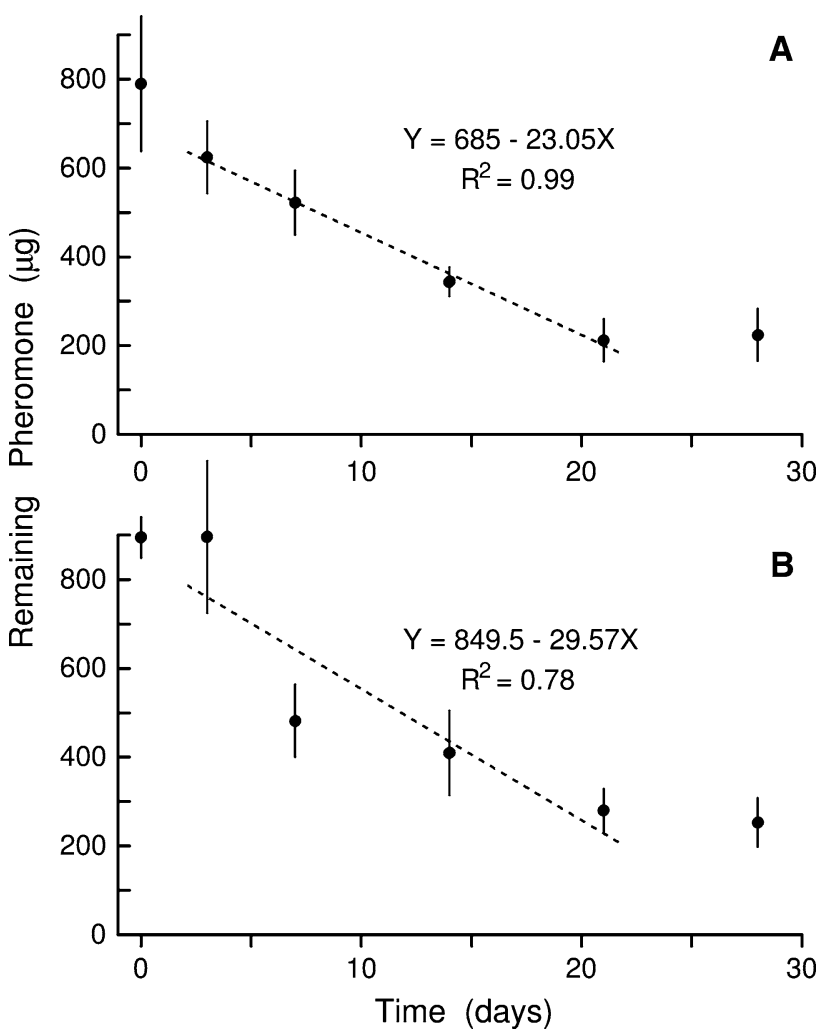

Fig. 5 Determination of release rates (equation slopes) of peach twig borer, Anarsia lineatella, pheromone ( $2.5 \mathrm{mg}$ initially) from sol-gel samples in the field during August 2004 based on amounts of pheromone remaining $( \pm \mathrm{SE})$ over time. a Release rate of $(E)-5$ decenyl acetate $(23 \mu \mathrm{g} /$ day $)$ in TMOS (90\%): MTMOS (10\%) matrix. b Release rate of $(E)$-5-decenyl acetate $(29.6 \mu \mathrm{g} /$ day $)$ in TMOS (80\%): MTMOS (20\%) matrix 


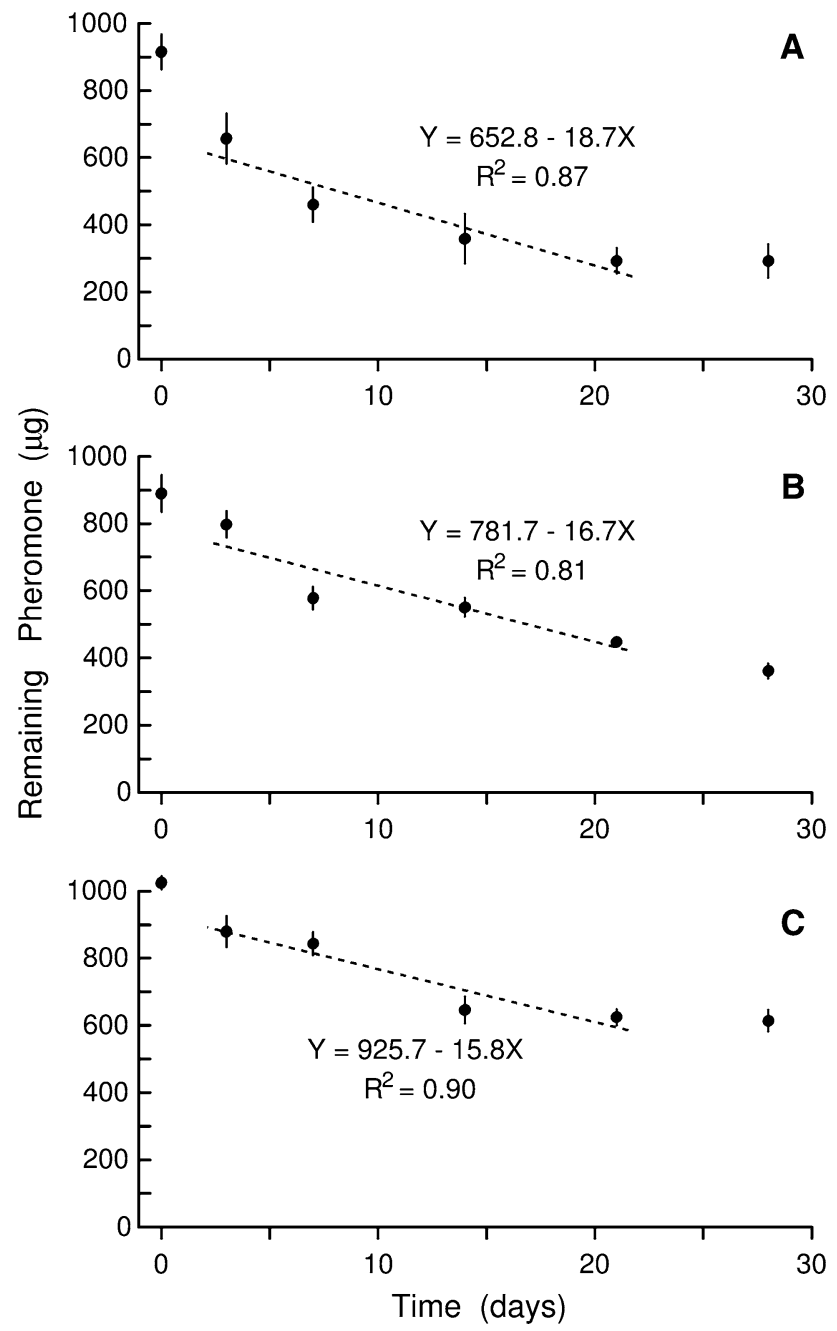

Fig. 6 Determination of release rates (equation slopes) of peach twig borer, Anarsia lineatella, pheromone ( $2.5 \mathrm{mg}$ initially) from sol-gel samples in the field during August 2004 based on amounts of pheromone remaining $( \pm \mathrm{SE})$ over time. a Release rate of $(E)-5$ decenyl acetate $(18.7 \mu \mathrm{g} /$ day $)$ in TMOS $(90 \%)$ : ETMOS $(10 \%)$ matrix. b Release rate of $(E)$-5-decenyl acetate $(16.7 \mu \mathrm{g} /$ day $)$ in TMOS (80\%): ETMOS (20\%) matrix. c Release rate of (E)-5-decenyl acetate $(15.8 \mu \mathrm{g} /$ day $)$ in TMOS $(60 \%)$ : ETMOS $(40 \%)$ matrix

seemed promising since it was homogeneous and visibly transparent. The alkylic tail of the alkyl trimethoxyorthosilicate comonomer (PTMOS) may enhance the lipophilicity of the gel. However, this monomer decreases the cross-linking and hence enlarges the cavities in which the pheromone can be trapped. The monomer also enlarges the microporous structure, resulting in pheromone loss. These factors were considered in "trial and error" tests to obtain a matrix with an appropriate slow release. In the first test (28 April to 9 May 2004) in the walnut orchard, five unbaited control traps caught no males, five traps with $30 \%$ PTMOS sol-gels impregnated with sex pheromone caught just 3 males (mean of $0.6 /$ trap, $n=5$ ) while $10 \%$ PTMOS caught 22 (mean of 4.4/trap, $P=0.046, t=2.35, d f=8$ ).

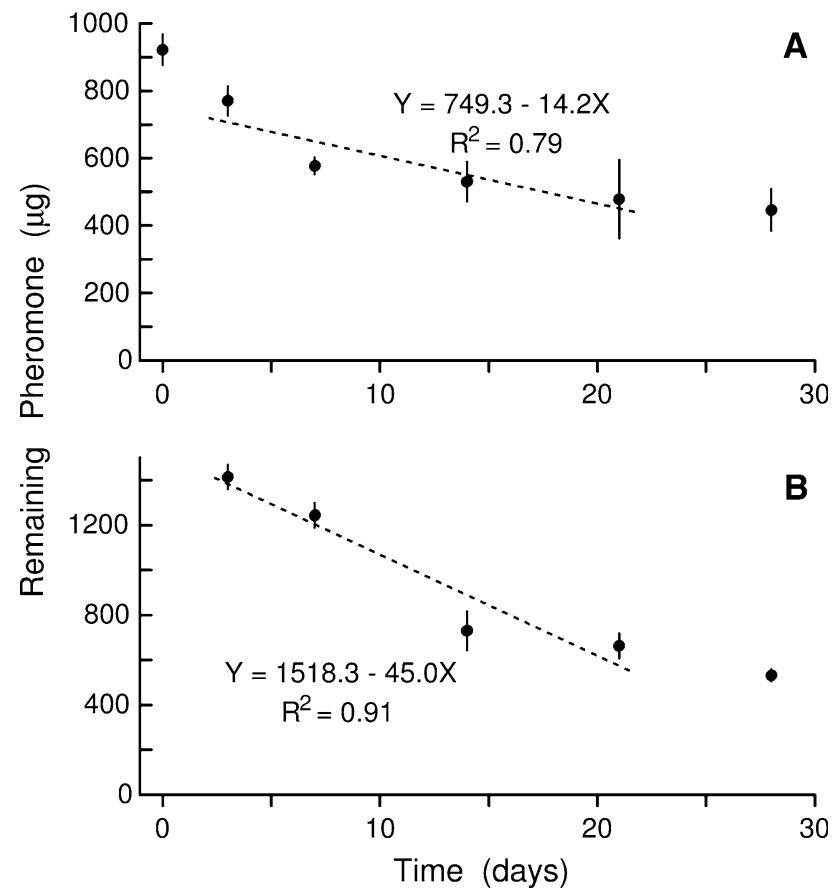

Fig. 7 Determination of release rates (equation slopes) of peach twig borer, Anarsia lineatella, pheromone ( $2.5 \mathrm{mg}$ initially) from sol-gel samples in the field during August 2004 based on amounts of pheromone remaining $( \pm \mathrm{SE})$ over time. a Release rate of $(E)-5$ decenyl acetate $(14.2 \mu \mathrm{g} /$ day) in TMOS $(90 \%)$ : PTMOS $(10 \%)$ matrix. b Release rate of $(E)$-5-decenyl acetate ( $45 \mu \mathrm{g} / \mathrm{day})$ in TMOS $(60 \%)$ : PTMOS $(40 \%)$ matrix

In subsequent tests (Tables 1 and 2), males were lured by other sol-gel preparations more so than by unbaited control traps. We noticed that our sol-gel matrices first shrank due to water loss and then degraded into small glass beads over a period of a few weeks under field conditions. The degradation products of the matrices are mostly silica and water that are both environmentally friendly.

\section{Discussion}

The relatively high volatility of insect pheromones required development of a new approach to the preparation of sol-gels. Most procedures to make sol-gels in the literature use heating or reduced pressure to eliminate by-products of the process, such as methanol and water, in order to achieve mechanical stabilization of the gel (Rao and Kulkarni 2002; Costa et al. 1997). Usually, the molecules to be entrapped are mixed with the reagents at the beginning of the preparation; then after the gel is formed, water and the solvent are evaporated. Since many pheromone components would likely not survive these conditions, this approach was unsuitable for our purposes. A second difficulty was the difference in lipophilicity between pheromones and sol-gels. The microenvironment in $\mathrm{SiO}_{2}$ 
Table 1 Total and mean numbers of codling moth (Cydia pomonella) males captured in traps baited with TMOS $+30,10,5$ OR $2 \%$ PTMOS sol-gels containing $(8 E, 10 E)$-dodecadienol sex pheromone

\begin{tabular}{|c|c|c|c|c|c|c|}
\hline \multirow[t]{3}{*}{ Treatment $^{\mathrm{a}}$} & \multicolumn{2}{|c|}{ 9-24 May 2004} & \multicolumn{2}{|c|}{24 May-3 June 2004} & \multicolumn{2}{|c|}{ 3-13 June 2004} \\
\hline & \multicolumn{2}{|l|}{ A } & \multicolumn{2}{|l|}{ B } & \multicolumn{2}{|l|}{$\mathrm{C}$} \\
\hline & Total & Mean/trap & Total & Mean/trap & Total & Mean/trap \\
\hline $30 \%$ PTMOS & 5 & 1.0 & 3 & 0.6 & 4 & 0.8 \\
\hline $10 \%$ PTMOS & 9 & 1.8 & 27 & $5.4^{\mathrm{b}}$ & 0 & 0.0 \\
\hline $5 \%$ PTMOS & 19 & $3.8^{\mathrm{b}}$ & 13 & $2.6^{\mathrm{b}}$ & 3 & 0.6 \\
\hline $2 \%$ PTMOS & 12 & 2.4 & 2 & 0.4 & 1 & 0.2 \\
\hline Ctrl (empty trap) & 3 & 0.6 & 1 & 0.2 & 0 & 0.0 \\
\hline
\end{tabular}

a Traps $(n=5)$ were exposed in a walnut orchard in Kibbutz Tzuba, Israel

b Catch was significantly different from unbaited control traps in the same column, $P<0.05$

Table 2 Dose response of codling moth (Cydia pomonella) males to elevated pheromone load in TMOS + 10\% PTMOS sol-gels

\begin{tabular}{|c|c|c|c|c|}
\hline \multirow[t]{3}{*}{ Treatment $^{\mathrm{a}}$} & \multicolumn{2}{|c|}{ 13-22 June 2004} & \multicolumn{2}{|c|}{22 June-1 July 2004} \\
\hline & \multicolumn{2}{|c|}{$\mathrm{D}$} & \multicolumn{2}{|l|}{$\mathrm{E}$} \\
\hline & Total & Mean/trap & Total & Mean/trap \\
\hline $10 \%$ PTMOS, $10 \mathrm{mg}$ & 22 & $4.4^{\mathrm{b}}$ & 8 & 1.6 \\
\hline $10 \%$ PTMOS, $2 \mathrm{mg}$ & 9 & 1.8 & 5 & 1.0 \\
\hline $10 \%$ PTMOS, $1 \mathrm{mg}$ & 8 & 1.6 & 7 & 1.4 \\
\hline $10 \%$ PTMOS, $0.5 \mathrm{mg}$ & 1 & 0.25 & 11 & 2.75 \\
\hline Ctrl (empty trap) & 2 & 0.4 & 3 & 0.6 \\
\hline
\end{tabular}

a Traps $(n=5)$ were exposed in a walnut orchard in Kibbutz Tzuba, Israel

${ }^{\mathrm{b}}$ Catch was significantly different from unbaited control traps in the same column, $P<0.05$

may be too polar for entrapment of a lipophilic molecule such as moth pheromones, therefore, the possibility was tested of combining $\mathrm{Si}\left(\mathrm{OCH}_{3}\right)_{4}$ and alkylsilanes $\mathrm{Si}\left(\mathrm{OCH}_{3}\right)_{3} \mathrm{R}$, where $\mathrm{R}$ is an alkyl non-hydrolyzable group. The latter monomer actually controls the cross-linking of the polymer and therefore the pore size, as does any polymer cross-linking agent.

So far, we have found no published reports on the entrapment of volatile molecules in sol-gels. A major limitation in the production of these materials is the relatively long time required for drying. There are two main drying techniques, classical and hypercritical drying, neither of which is conducive for pheromone entrapment. This is because our experience suggests it would be preferable to entrap the pheromone in the gel after completion of drying, or to avoid the drying process completely to reduce losses and degradation of the pheromone.

We found that beyond five days after the preparation of the matrix, only $60-70 \%$ of the pheromone could be extracted from the sol-gel by common solvents such as THF, methanol, or acetone. Introduction of a guest molecule is usually performed by adding the dopant to the polymerization mixture, so that when the polymerization is completed, the guest compound is entangled with the inorganic matrix. The nature of these interactions is not fully understood: the molecules may be trapped, adsorbed on pore surfaces, or chemically bound into the inorganic structure. There are also difficulties in producing these materials with ideal characteristics, since the quality of the sol-gel depends on specific steps in the procedure, mostly in the gel-drying process. Organic compounds, particularly volatile ones such as pheromones, rarely survive temperatures above $200^{\circ} \mathrm{C}$ during such processes. Levy and Esquivias (1995) reported that incorporation of organic dyes into sol-gels and drying, even at temperatures below $150^{\circ} \mathrm{C}$, resulted in cracking, shrinkage and high porosity, which facilitated the leaching of the small molecules. Moreover, it is likely that some of the pheromone was trapped within cavities in the matrix that are accessible only through micropores, through which the pheromone molecules were too large to pass.

Our results demonstrate the concepts and properties needed to prepare sol-gel matrices for slow-release of semiochemicals. Sol-gel matrices doped with pheromones were developed and the model matrices released the moth pheromones at almost constant rates for up to a month even under field conditions during mid summer (August 2004) in a Mediterranean climate. However, further development of sol-gel matrices with uniform pore sizes is needed to improve the reproducibility of release rates and to facilitate the preparation of superior pheromone lures. In mating disruption programs, when higher doses of pheromone are needed to be employed, the amorphous nature of sol-gels allows manipulation of semiochemical release rates simply by increasing pheromone/sol-gel ratios and the sol-gel quantity. Furthermore, one or more of the seven pheromone components we entrapped in sol-gels are reported to be attractive to at least 359 moth species (Byers 2006; El-Sayed 2008), indicating the wide applicability of our 
methods. Other pheromone components, especially more polar types, appear suitable for release by sol-gels but further work is needed. Sol-gels in our study had a constant release rate of pheromone that is desirable compared with currently used substrates (e.g., wax dollops, rubber septa, plastic vials, cotton rolls) that exhibit exponentially declining release rates (Flint et al. 1978; Bierl-Leionhardt 1982; McDonough 1991; Knight 1995; Johansson et al. 2001; Zada et al. 2002; Stelinski et al. 2005). Our release rates of peach twig borer pheromone ranged from 14 to $45 \mu \mathrm{g} /$ day from sol-gels initially impregnated with $2.5 \mathrm{mg}$ of pheromone, which compares satisfactorily with releases of moth pheromones from rubber septa (16C aldehydes in field: Scentry gray septum: $10.7 \mu \mathrm{g} /$ day, Trece red septum: $45 \mu \mathrm{g} /$ day, Knutson et al. 1988). Similar releases were found by Flint et al. (1978) who applied from 1 to $12 \mathrm{mg}$ of pink bollworm pheromone to rubber septa and obtained optimal field catches with release rates of from $5 \mu \mathrm{g}$ to $48 \mu \mathrm{g} /$ day, respectively. Further development of sol-gel formulations for monitoring lures and mating disruption dispensers should allow optimization of release rates for efficient management of insect pests with particular pheromones in the field. Another advantage that should be emphasized is that use of sol-gels is environmentally friendly and safe because the degradation products are mostly water and silica.

Acknowledgments We would like to thank the GIF Young-Scientists Foundation, Program No. G-2057-1179.12/2002 for supporting this research. We thank Mrs Ariela Niv of the Israeli Cotton Board and Mrs Miriam Harel of Institute of Plant Protection, ARO for their assistance. In addition we thank Dr. Ezra Dunkelblum, Institute of Plant Protection, ARO and Prof. Albert Zilkha, Dept. of Organic Chemistry, The Hebrew University of Jerusalem for helpful consultations and Mark Sarrabia, pest-supervisor of the orchards in Kibbutz Tzuba, for allowing us to conduct our experiments in the walnut orchard.

\section{References}

Atterholt CA, Delwiche MJ, Rice RE, Krocht JM (1998) Study of biopolymers and paraffin as potential controlled-release carriers for insect pheromones. J Agric Food Chem 46:4429-4434

Avnir D (1995) Organic chemistry within ceramic matrices: doped sol-gel materials. Acc Chem Res 28:328-334

Bartelt RJ, Vetter RS, Carlson DG, Baker TC (1994) Influence of pheromone dose, trap height, and septum age on effectiveness of pheromones for Carpophilus mutilatus and C. hemipterus (Coleoptera: nitidulidae) in a California date garden. J Econ Entomol 87:667-675

Bierl-Leonhardt BA (1982) Release rates from formulations and quality control methods. In: Kydonieus AF, Beroza M (eds) Insect suppression with controlled release pheromone systems, vol. 1. CRC Press, Boca Raton, pp 245-258

Brown DF, Knight AL, Howell JF, Sell CR, Krysan JL, Weiss M (1992) Emission characteristics of a polyethylene pheromone dispenser for mating disruption of codling moth (Lepidoptera: Tortricidae). J Econ Entomol 85:910-917
Byers JA (1988) Novel diffusion-dilution method for release of semiochemicals: testing pheromone component ratios on western pine beetle. J Chem Ecol 14:199-212

Byers JA (2006) Pheromone component patterns of moth evolution revealed by computer analysis of the Pherolist. J Anim Ecol 75:399-407

Byers JA (2007) Simulation of mating disruption and mass trapping with competitive attraction and camouflage. Environ Entomol 36:1328-1338

Byers JA (2008) Active space of pheromone plume and its relationship to effective attraction radius in applied models. $\mathbf{J}$ Chem Ecol 34:1134-1145

Chamberlain DJ, Brown NJ, Jones OT, Casagrande E (2000) Field evaluation of a slow release pheromone formulation to control the American bollworm, Helicoverpa armigera (Lepidoptera: Noctuidae) in Pakistan. Bull Entomol Res 90:183-190

Cork A, De Souza K, Hall DR, Jones OT, Casagrande E, Krishnaiah K, Syed Z (2008) Development of PVC-resin-controlled release formulation for pheromones and use in mating disruption of yellow rice stem borer, Scirpophaga incertulas. Crop Prot 27:248-255

Costa TMH, Stefani V, Balzaretti N, Francisco LTST, Gallas MR, Da Jornada JAH (1997) High pressure loading of organic dyes into a silica matrix. J Non-Cryst Solid 221:157-162

deLame FM, Miller JR, Atterholt CA, Gut LJ (2007) Development and evaluation of an emulsified paraffin wax dispenser for season-long mating disruption of Grapholita molesta in commercial peach orchards. J Econ Entomol 100:1316-1327

Dunkelblum E, Kehat M, Klug JT, Shani A (1984) Trimerization of Earias insulana sex pheromone (E, E)-10, 12-hexadecadienal, a phenomenon affecting trapping efficiency. J Chem Ecol 10:421428

El-Sayed AM (2008) The pherobase: database of insect pheromones and semiochemicals (http://www.pherobase.com)

El-Sayed AM, Suckling DM, Wearing CH, Byers JA (2006) Potential of mass trapping for long-term pest management and eradication of invasive species. J Econ Entomol 99:1550-1564

Ferrer ML, Del Monte F, Levy D (2002) A novel and simple alcoholfree sol-gel route for encapsulation of labile proteins. Chem Mater 14:3619-3621

Flint HM, Butler L, McDonaough LM, Smith RL, Forey DE (1978) Pink bollworm: response to various emission rates of gossyplure in the field. Environ Entomol 7:57-61

Ideses R, Shani A (1988) Chemical protection of pheromones containing an internal conjugated diene system from isomerization and oxidation. J Chem Ecol 14:1657-1669

Johansson BG, Anderbrant O, Simandl J, Avtzis ND, Salvadori C, Hedenstrom E, Edlund H, Hogberg HE (2001) Release rates for pine sawfly pheromones from two types of dispensers and phenology of Neodiprion sertifer. J Chem Ecol 27:733-745

Kandimalla VB, Tripathi VS, Ju HX (2006) Immobilization of biomolecules in sol-gels: biological and analytical applications. Crit Rev Anal Chem 36:73-106

Knight AL (1995) Evaluating pheromone emission rate and blend in disrupting sexual communication of codling moth (Lepidoptera: Tortricidae). Environ Entomol 24:1396-1403

Knutson AE, Davis FM, Hedin PA, Phillips VA (1988) Field evaluation of eight substrates for dispensing pheromone of the southwestern corn borer (Lepidoptera: Pyralidae). J Econ Entomol 81:1474-1477

Kroschwitz JI, Howe-Grant M (eds) (1998) Kirk-othmer encyclopedia of chemical technology, 4th edn (suppl). Wiley, New York, pp 1-22

Levy D, Esquivias L (1995) Sol-gel processing of optical and electrooptical materials. Adv Mater 7:120-129 
McDonough LM (1991) Controlled release of insect sex pheromone from a natural rubber substrate. In: Hedin PA (ed) Naturally occuring pest bioregulators. Amer Chem Soc Symp Ser, vol. 449, pp 106-124

McLaughlin JR, Heath RR (1989) Field trapping and observations of male velvetbean caterpillar moths and trapping of Mocis spp. (Lepidoptera: Noctuidae: Catacolinae) with calibrated formulations of sex pheromone. Environ Entomol 18:933-938

Millar JG (1995) Degradation and stabilization of E8, E10-dodecadienol, the major component of the sex pheromone of the codling moth (Lepidoptera: Tortricidae). J Econ Entomol 88:1425-1432

Miller JR, Gut LJ, deLame FM, Stelinski LL (2006a) Differentiation of competitive vs. non-competitive mechanisms mediating disruption of moth sexual communication by point sources of sex pheromone (Part 1): theory. J Chem Ecol 32:2089-2114

Miller JR, Gut LJ, deLame FM, Stelinski LL (2006b) Differentiation of competitive vs. non-competitive mechanisms mediating disruption of moth sexual communication by point sources of sex pheromone (Part 2): case studies. J Chem Ecol 32:2115-2143

Rao AV, Kulkarni MM (2002) Hydrophobic properties of TMOS/ TMES-based silica aerogels. Mater Res Bull 37:1667-1677

Sokal RR, Rohlf FJ (1995) Biometry. W.H. Freeman, New York

Stelinski LL, Gut LJ, Mallinger RE, Epstein D, Reed TP, Miller JR (2005) Small plot trials documenting effective mating disruption of significant populations of oriental fruit moth, Grapholita molesta (Busck), using high densities of wax-drop pheromone dispensers. J Econ Entomol 98:1267-1274

Stelinski LL, Miller JR, Ledebuhr R, Siegert P, Gut LJ (2007a) Season-long mating disruption of Grapholita molesta (Lepidoptera: Tortricidae) by one machine application of pheromone in wax drops (SPLAT-OFM). J Pest Sci 80:109-117
Stelinski LL, Gut LJ, Haas M, McGhee P, Epstein D (2007b) Evaluation of aerosol devices for simultaneous disruption of sex pheromone communication in Cydia pomonella and Grapholita molesta (Lepidoptera: Tortricidae). J Pest Sci 80:225-233

Suckling DM (2000) Issues affecting the use of pheromones and other semiochemicals in orchards. Crop Prot 19:677-683

Todd JL, Millar JG, Vetter RS, Baker TC (1992) Behavioral and electrophysiological activity of (Z, E)-7, 9, 11-dodecatrienal formate, a mimic of the major sex pheromone component of carob moth, Ectonyelois ceratoniae. J Chem Ecol 18:2331-2352

Vrkoč J, Konečý K, Valterová I, Hrdý I (1988) Rubber substrates and their influence on isomerization of conjugated dienes in pheromone dispensers. J Chem Ecol 14:1347-1358

Wilkins RM, McGuffog DR, Anerson TP, Plimmer JR, Pickett JA, Dawson GW, Griffith DC, Liu X, MaCauly EDM, Woodcock CM, Lie R, Meghir S (1984) Pesticides group symposium-recent developments in controlled release formulations for pest control. Pest Sci 15:258-267

Zada A, Soroker V, Harel M, Nakache J, Dunkelblum E (2002) Quantitative GC analysis of secondary alcohols pheromones: determination of the release rate of the red palm weevil, Rhynchophorus ferrugineus, pheromone from lures. J Chem Ecol 28:2279-2286

Zayat M, Garcia-Parejo P, Levy D (2007) Preventing UV-light damage of light sensitive materials using a highly protective UVabsorbing coating. Chem Soc Rev 36:1270-1281

Zdarek J, Vrkoč J, Hochmut R, Kolk A (1988) Male confusion on the nun moth with dispalure at high and low population densities. J Chem Ecol 14:537-547 